\title{
Clinical Study of Ectopic Pregnancy in Al-Zahra Teaching
}

\author{
Dr. Mahassin Qassim Qaddori \\ MB.chB ,Diploma in gynecology and obstetrics Baghdad university college of medicine
}

\begin{abstract}
An ectopic pregnancy is one in which fertilized ovum is implanted at the site other than normal uterine cavity.[1] Incidence of ectopic pregnancy is 1:160 deliveries.[2]Clinical presentation is variable from acute to chronic type. Due to its varied clinical presentation ectopic pregnancy poses great diagnostic difficulty both to obstetrician, physician and surgeons.[3] OBJECTIVE: To find out incidence in our study population and to evaluate symptomatically and clinical presentation in these patients. MATERIALS AND METHODS: Retrospective study of 34 ectopic pregnancies admitted and treated in Al-zahra Teaching Hospital from 2015 to 2020 are included in the study. RESULTS: The incidence of ectopic pregnancy is more between the age group of 2130years (73.52\%) and in Multigravida $64.71 \%$. Infertility and previous tubal surgery are the high risk factors for tubal pregnancy. Pain in abdomen was present in all 34 cases, amenorrhea in $97.05 \%$ and bleeding per vagina in $76.47 \%$ cases. Syncopal attacks, vomiting were detected in $14.70 \%$ cases. Acute ectopic pregnancy was detected in $14.71 \%$ and chronic in $85.29 \%$ cases. $82.35 \%$ cases presented with adnexal mass, $79.41 \%$ with cervical motion tenderness, $50 \%$ with pallor, $32.35 \%$ with abdominal lump and tenderness and $11.76 \%$ with fullness in POD. CONCLUSION: Ectopic pregnancy is leading cause of maternal mortality in first trimester. In spite of advanced diagnostic techniques. It poses great diagnostic difficulties due to varied signs and symptoms. Previous tubal surgery pelvic inflammatory disease and infertility are the risk factors of tubal pregnancy.
\end{abstract}

KEYWORDS: Ectopic pregnancy, Salpingectomy, Ovarian pregnancy.

DOI: $10.7176 / \mathrm{JHMN} / 81-03$

Publication date:October $31^{\text {st }} 2020$

\section{INTRODUCTION}

Ectopic Pregnancy is one in which fertilised ovum gets implanted at the site other than normal uterine cavity.[1] Tubal pregnancy is not synonymous but the most common type of ectopic pregnancy. Albucasis, the Arabian surgeon discovered the first case of ectopic pregnancy. Foetal bones were extruded from umblicus in this case and was a case of secondary abdominal pregnancy. Incidence of ectopic pregnancies varies from place to place and it is more common in the area where there is more prevalence of STD's, genital tract TB and post abortal and puerperal sepsis. Partial tubal block due to salpingitis, tubal surgery, abdominal surgery etc. is the single most important cause for tubal pregnancy. Clinically its presentation is variable from acute to chronic. Diagnosis of acute ectopic is easy but chronic ectopic presents differently in different patients, making pitfalls in diagnosis. Thus due to disparity of its signs and symptoms, ectopic pregnancy has become interesting and challenging problem to the gynaecologist for timely diagnosis and intervention. With respect to the management of ectopic pregnancy, there have been tremendous technical advances. The early diagnosis and treatment of this condition over the past two decades has allowed a definitive medical management of unruptured ectopic pregnancies even before there were clinical symptoms in these high risk women.[4,5] DOI: OBJECTIVES: 1 . To find out the incidence of ectopic pregnancy in study population. 2. To evaluate symptomatology and clinical presentation of ectopic pregnancy and 3 . To analyse morbidity and mortality occurring in these patients.

\section{MATERIALS AND METHODS}

This study is based on clinical diagnosis and management of Ectopic Pregnancy of patients who reported at AlZahra Teaching Hospital from Jan 2015 to Aug 2020. It is a retrospective analysis of 34 patients. During same periods there were 5449 deliveries giving the incidence of ectopic pregnancy 1 in 160 deliveries. All patients with history suggestive of ectopic pregnancy and in whom diagnosis was confirmed by clinical findings, ultrasound and direct visualisation at laparotomy are included in the study.

\section{OBSERVATION AND ANALYSIS: Results}

1-Showing Incidence of Ectopic Pregnancy According to the Age. e $<=$ age20 years .frequency 5.percentage 14.70/ age21-25.frequency 15.percentage . 44.11/ age 26- 30.frequency 10.percentage 29.41/age 3135.frequency 3.percentage 08.83/age 36-40.frequency 1.percentage 02.95 .

2-Showing Incidence of Ectopic Pregnancy According to the Gravidity. . . Primi .Frequency

12 .percentage35.29 .multi .frequency 22.percentage 64.71.

3-Showing of various symptoms in Ectopic Pregnancy Symptoms... Amenorrhea.Frequency 33.percentage 97.05 Pain in abdomen.Frequency 34 percentage 100 . Bleeding p/v Frequency 26 percentage 76.47. Other associated symptoms Frequency 5 percentage 14.70. 
4-Showing Percentage. Acute and Chronic Ectopic Pregnancy Acute Frequency 5.percentage 14.71. Chronic.Frequency 29 .percentage 85.29 . -

5: Showing Percentage of the different signs in Ectopic Pregnancy Findings. Pallor Frequency 17 percentage 50.00 - - Abdominal lump. Frequency 11 percentage 32.35.cervical Tenderness Frequency 27 percentage 79.41. Mass in fornices-Frequency 28 percentage 82.35

6: Showing Percentage of UPT interpretation in Ectopic Pregnancy USG finding Frequency Percentage .POSITIVE Frequency 28 percentage 82.35. NEGATIVE Frequency 6 percentage 17.65

7: Showing the USG findings in Ectopic pregnancy .Right adnexal mass Frequency 22 percentage 64.70. Left adnexal mass Frequency 12 percentage35.29 Empty uterus Frequency 34 percentage 100 Fluid in POD Frequency 7 percentage 20.5888 Table

8: Showing the Fate of Tubal Pregnancy Site of ectopic gestation .Laparotomy-fate of ectopic gestation in tubal pregnancy. Tubal rupture. Frequency27 percentage 79.41.Tubal abortion Frequency 4 percentage 11.76. Unruptured .Frequency2 percentage 05.

9: Showing incidence of the Site of Ectopic Pregnancy.Ampullary.Frequency 24 percentage 70. Isthmic Frequency 7 percentage 20.58 Fimbrial Ferquency 2 percentage 05.88 ovarian Frequency 1 percentage 0.2.94

10: Showing Incidence According to The Type of Treatment Modality. Medical .Frequency 2 percentage 05.88 . Surgical Frequency 30 percentage 88.24 Conservative surgery Frequency 2 percentage 05.88

11: Showing Incidence of The Blood Transfusion for Management .No transfusion given .Frequency 14 percentage 41.17 Transfusion given .Frequency 20 percentage 58.83

12: Showing Amount of Blood Loss in Ectopic Pregnancy Nil .Frequency 2 percentage 05.88 . Upto 500ml Frequency 10 percentage $29.41 .500-1000 \mathrm{ml}$ Frequency 17 percentage $50.00 \cdot 1000-1500 \mathrm{ml}$ Frequency 2 percentage 05.88 .More than $1500 \mathrm{ml}$ Frequency 3 percentage 08.8

\section{DISCUSSION}

The maximum incidence in this series is between the age group of $21-30$ years $(44.11 \%+29.41 \%=73.52 \%)$. The maximum age of patient is 36 years and minimum 19 years. The incidence of ectopic pregnancy decreases with increasing age. Rashmi et al conducted a study in which $70.2 \%$ cases belonged to the age group of 21-30 years.[6] The incidence of ectopic pregnancy in Multigravida is $64.71 \%$ and that of primigravida is $35.29 \%$. the incidence in multigravida is high as they are more exposed to post abortal, puerperal infections and STD's. In the study conducted by Rashmi et al in June 2012, 60.2\% cases were multigravida and rest were 37.8\%.[6] In the present series $5(14.71 \%$ ) cases were taking treatment for infertility and previous ectopic was found in $2.94 \%$ cases. 4 cases had undergone tubectomy in the past $(11.76 \%)$ and in 2 cases tubal recanalization was done. this shows that Infertility and previous tubal surgery is the high risk factor for tubal pregnancy. in the study conducted by Rashmi et al in June 2012 there was history of tubectomy in $16.21 \%$ cases and $16.21 \%$ had history of infertility and previous ectopic pregnancy was found in $2.7 \% .[6]$ in our study history of previous ectopic were in $2.94 \%$ cases. In this study pain in abdomen was present in all 34 cases, followed by amenorrhea which was present in $97.05 \%$ cases and bleeding $\mathrm{P} / \mathrm{V}$ in $76.47 \%$ cases. Other associated symptoms such as syncopal attacks, vomiting were detected in $14.70 \%$ cases. This shows that in ectopic pregnancy pain in abdomen, amenorrhea and bleeding $\mathrm{P} / \mathrm{V}$ is most frequent symptom still absence of amenorrhea and bleeding $\mathrm{P} / \mathrm{V}$ cannot rule out ectopic pregnancy. In study conducted by Rashmi et al in June 2012 amenorrhea in $77.5 \%$, pain in abdomen in $89.2 \%$, bleeding $\mathrm{p} / \mathrm{v} 42.3 \%$.[6] In the present series acute ectopic pregnancy was detected in $14.71 \%$ and chronic in $85.29 \%$ cases showing chronic ectopic has a most common clinical presentation in ectopic pregnancy. In present study $82.35 \%$ presented with adnexal mass, $79.41 \%$ with cervical motion tenderness, $76.47 \%$ had bleeding $\mathrm{p} / \mathrm{v}$, $50 \%$ with pallor, $32.35 \%$ with abdominal lump and tenderness and $11.76 \%$ with fullness in POD. In 13 cases (38.23\%) HGM \% was found normal and in 21(61.76\%) patients were anaemic, out of which $3(08.82 \%)$ were severely anaemic, $11(32.35 \%)$ had moderate anaemic and $7(20.58 \%)$ were mildly anaemic. $82.35 \%$ had a positive Urine Pregnancy Test and $17.65 \%$ had negative reading. This shows that negative pregnancy test cannot rule out ectopic pregnancy. Rashmi et al conducted a study in 2012 June which stated UPT positive in $97.3 \%$ cases and $2.7 \%$ cases reported a negative UPT. USG was performed in all cases. Adnexal mass and empty uterus was detected in all cases and fluid in POD was noted in 32(94.11\%) cases. the classic findings of empty uterus, non-specific complex adnexal mass, fluid in POD are demonstrated in almost all cases when this classic finding along with positive urine pregnancy test is present, the diagnosis of chronic ectopic can be made accurately. Diagnosis of Intact tubal pregnancy can be made accurately from ultrasonographic findings by detecting $\mathrm{G}$ sac outside the uterine cavity. Rashmi et al study stated that $83.2 \%$ had adnexal mass as a ultrasonographic finding. [6] In the present series 33 cases were of tubal pregnancy and 1 of ovarian pregnancy. Out of 33 tubal pregnancy tubal rupture was seen in 27 cases $(79.41 \%)$, tubal abortion in 4 cases $(11.76 \%)$ and unruptured tubal pregnancy in $(05.88 \%)$ cases. This shows tubal rupture is the most common fate of tubal pregnancy. In the study conducted by Rashmi et al June 2012 tubal rupture was found in $78.3 \%$ cases and unruptured in $8.1 \%$ cases.[6]Wills and Mohmbi et al detected ruptured tubal pregnancy in $66 \%$ cases and unruptured in $34 \%$ cases.[7] 
$24(70.58 \%)$ cases had ampullary region tubal ectopic gestation, $7(20.58 \%)$ isthmic, $1(2.94 \%)$ infundibular, 1 (2.94\%) fimbrial. this shows that ampullary region tubal ectopic is the most common site for tubal ectopic gestation.[8] 30 cases (88.24\%) underwent unilateral salphingectomy. 2(5.88\%) cases were treated with methotrexate $1 \mathrm{mg} / \mathrm{kg}$ of body weight and in $2(5.88 \%)$ cases milking was performed with postoperative methotrexate therapy.[9]In the study conducted by Rashmi et al in june $201267.6 \%$ cases were treated by salpingectomy, $5.4 \%$ by milking for tubal abortion.[10,11] 20(58.88\%) of patients recovered with 2 units of blood transfusion. 2 cases 4units of blood transfusion. 50\% patients had blood varying from 500-1000ml in the peritoneal cavity, $29 \%$ upto $500 \mathrm{ml}, 8.83 \%$ had blood loss of more $1500 \mathrm{ml}$.

\section{CONCLUSION}

1) Ectopic pregnancy is the disaster of reproduction and inspite of modern diagnostic technologies it is the leading cause of maternal mortality in the first trimester of pregnancy. 2) Previous ectopic, abdominal and tubal surgeries are the risk factors for tubal pregnancy. 3) One should be vigilant to rule out ectopic pregnancy in all patients in reproductive age group complaining of pain in abdomen with or without history of amenorrhoea, and bleeding per vagina. 4) With the classic findings in USG of empty uterus, non-specific complex adnexal mass, fluid in POD along with positive urine pregnancy test, the diagnosis of chronic ectopic can be made accurately. 5) Un-ruptured tubal pregnancy with gestational sac diameter less than $4 \mathrm{~cm}$ can be managed conservatively by medical therapy. 6) Salpingectomy is most common treatment for ruptured tubal pregnancy, but in patient who want to preserve reproductive function, can be treated by conservative tubal surgeries such as milking of tube and methotrexate therapy in selected cases.

\section{REFERENCES}

1. Ectopic Pregnancy - United States, 1990-92. JAMA 1995; 273:533.

2. Rajkhowa M, Glass MR, Rutherford AJ, Balen AH, Sharma V, Cuckle HS. Trends in the incidence of ectopic pregnancy in England and Wales from 1966-1996. Br J Obstet Gynaecol 2000 March; 107:369-74.

3. Department of Health: Why mothers die: a confidential enquiry into the maternal deaths in the United Kingdom. In Drife J, Lewis G (eds): Norwich, UK: HMSO, 2001; 282.

4. Stovall TG, Ling FW, Buster JE. Outpatient chemotherapy of unruptured ectopic pregnancies. Fertil Steril 1989; $51: 435$.

5. Stovall TG, Ling FW, Gray LA, Carson SA, Buster JE. Methotrexate treatment of unruptured ectopic pregnancies: a report of 100 cases. Obstet Gynaecol 1991; 77:749.

6. Rashmi A Gaddgi et al, Journal of clinical and diagnostic research 2012 June vol-6(5):,867-869.

7. Sultana CJ, Easley K, Collins RL. Outcome of laparoscopic vs traditional surgeries for ectopic pregnancies. Fertil Steril 1992; 57:285.

8. Delacruz A, Cumming DC. The factors which determine the fertility after a conservative or radical surgical treatment for ectopic pregnancy. Fertil Steril 1997; 68:871.

9. Comprehensive Gynaecology, 3rd edition. Missouri, St Louis: Mosby 1997; 432.

10. Cacciatore B, Stenman UH, Yiostalo P. Diagnosis of ectopic pregnancy by vaginal ultrasonography in combination with a discriminatory serum HCG level of 1000 IU/L (IRP). Br J Obstet Gynaecol 1990; 97:904.

11. Stabile J, Grudzinskas JG. Ectopic pregnancy: A review of the inci- dence, etiology and the diagnostic aspects. Obstet Gynaecol Surv 1990; 45:335. 